\title{
Influence of Menstrual Cycle on Pharmacokinetics of Ciprofloxacin
}

\author{
*Sandhya Rani Guggilla, Swathi Konda, Sarangapani Manda.1 \\ Post Doctoral fellow, university college of pharmaceutical sciences, kakatiya university \\ 1 Professor, university college of pharmaceutical sciences ,kakatiya university
}

\begin{abstract}
The aim of our research work is to study the influence of menstrual cycle on the pharmacokinetic parameters of the Ciprofloxacin in patients with infections. Plasma samples were collected from 12 female patients on long term oral Ciprofloxacin monotherapy (not less than two years) with prescribed dosage regimen dose at the time points of $0,1,2,3,4,6,8$ \& 12 hours after dosing and analysed for drug content by HPLC method. Mean Cmax of Ciprofloxacin was decreased by $20 \%$ in the ovulatory phase compared to that of follicular phase. The AUCO- $\infty$ of Ciprofloxacin i.e, bioavailability was decreased in luteal phase by $20 \%$ than follicular phase. Volume of distribution of Ciprofloxacin was significantly lower in follicular and luteal phases compared to ovulatory phase. Ciprofloxacin half-life was decreased and clearance was increased in luteal phase compared to follicular phase. Except Vd/f and Vss/f, menstrual cycle phases did not significantly affect

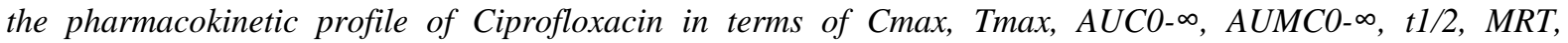
clearance and absorption rate constant. From the above observations it can be concluded that, menstrual hormonal changes influenced Ciprofloxacin pharmacokinetics to a lesser extent and Vd/f and Vss/f were significantly altered. Mean plasma concentrations of Ciprofloxacin were higher in follicular phase than in ovulatory and luteal phases.
\end{abstract}

Keywords: Menstrual cycle - Plasma samples - Ciprofloxacin.

\section{Introduction}

CIPROFLOXACIN plasma concentrations are decreased by self-induction of microsomal enzymes after few weeks of therapy, which occasionally needs increased dosage to sustain effective therapeutic levels. It has narrow therapeutic index and complex pharmacokinetic properties, monitoring its concentration for better clinical management of patients is therefore required. The biological factors that influence the pharmacokinetics of CIPROFLOXACIN include food, age, sex etc., inturn modify time to reach maximal plasma concentration, which alters its concentration at receptor sites and influences the pharmacodynamic action. Nonethless, these factors play a significant role on drugs with narrow therapeutic rangeeither precipitates the adverse effects or masks the therapeutic action. Drug concentration maintenance plays a vital role in drugs with narrow margin of safety to overcome the therapeutic failure on one hand and to decrease the adverse effects on the other hand. Ovarian hormones alter physological functions and thereby modify absorption, distribution, metabolism and excretion of drugs which inturn modulate pharmacodynamics. The level of female hormones is phase specific and the pharmacokinetic parameters of drugs are altered by the cyclic changes in menstrual cycle. Variability in pharmacokinetics during different phases of menstrual cycle is demonstrated with Antipyrine ${ }^{12}$, Methaqualone ${ }^{13}$, Theophylline ${ }^{14}$, Caffeine ${ }^{15}$, Zidovudine ${ }^{16}$ and Midazolam.The aim of the present research work is to study the influence of menstrual cycle (i.e., follicular phase, ovulatory phase and luteal phase) on pharmacokinetic parameters of Ciprofloxacin in patients.

\section{Patients And Methods}

12 female patients with their body weights ranging from 40 to $60 \mathrm{kgs}$, height 140 to $160 \mathrm{cms}$ and age 22 to 30 years were included in the study. The study protocol was approved by the Institutional Ethical Committee. Patients with regular menstrual cycle, not suffering from any other chronic disease not using any other drug except Ciprofloxacin were included in the study .

\section{Patient selection}

The female patients were selected from the patients who visited antibiotic department as out patients in the Warangal General Hospital, Warangal, after taking due permission from that department and written informed consent was obtained from all the patients who were willing to participate in the study. 12 female patients who complied inclusion criteria and on long term oral Ciprofloxacin therapy (not less than 2 years) with prescribed dosage regimen as per physician's prescription 500mg were selected for the study. Plasma samples were collected from each patient prior to the morning dose $(0 \mathrm{~h})$ and at the time points of $1,2,3,4,6,8 \& 12$ hours after dosing. Plasma samples were collected after cleaning the tongue debris and mouth every time before 
sampling, which were stored at $-80^{\circ} \mathrm{C}$ until further analysis. Plasma samples containing Ciprofloxacin were measured by HPLC method, on reverse phase C -18 column with a total analytical time less than 6.5 minutes ${ }^{24}$.

\section{Chromatographic conditions}

Mobile phase consisting of methanol: water: glacial acetic acid (67: 33: $1 \mathrm{v} / \mathrm{v} / \mathrm{v})$ was prepared and mixed thoroughly, degassed and used for the HPLC analysis. $1.0 \mathrm{ml}$ per minute flow rate was maintained throughout the analysis. The eluent was monitored using a UV-VIS detector set at $280 \mathrm{~nm}$ and sensitivity was set at 0.001 a.u.f.s.

\section{Preparation of standard graph Standard solutions}

Stock solutions of $100 \mu \mathrm{g} / \mathrm{ml}$ each of oflaxacin and Ciprofloxacin were prepared in methanol. These solutions were further diluted with methanol to the required concentrations of each drug and stored at $-4^{\circ} \mathrm{C}$. For the preparation of standard graph $0.1,0.5,1,5,10,50$ and $100 \mu \mathrm{g} / \mathrm{ml}$ of Ciprofloxacin in plasma was used.

\section{Patient plasma extraction procedure}

To each $100 \mu \mathrm{l}$ of plasma sample, $20 \mu \mathrm{l}$ of internal standard $(500 \mu \mathrm{g} / \mathrm{ml}$ Ofloxacin solution) was added and extracted with $1.7 \mathrm{ml}$ of ethyl acetate, vortexed for $1 \mathrm{~min}$ and centrifuged at 13,000 rpm for $8 \mathrm{~min}$. The supernatant was evaporated to dryness and the residue was reconstituted with $100 \mathrm{ul}$ of mobile phase, vortexed for $1 \mathrm{~min}$. and 20ul was injected onto HPLC. The standard solutions were also processed by similar extraction procedure. The retention times were $5.1 \mathrm{~min}$. and $6.0 \mathrm{~min}$. for doxycycline and Ciprofloxacin respectively. The peak area ratios obtained at different concentrations of the drug were plotted against the concentrations of the drug. The slope of this plot was calculated by least square regression analysis and was used to calculate Ciprofloxacin concentration in unknown plasma samples. Data was analysed for pharmacokinetic parameters by using WINNONLINE software.

\section{Analysis of blank blood samples for hormones}

The blank blood samples were collected from the patients before administration of the drug (0h) and analysed for concentrations of estrogen and progesterone hormones by the Chemiluminisence method..

\section{Results And Discussion}

The mean plasma Ciprofloxacin levels versus time in three phases of menstrual cycle were shown in Fig.1, the plasma Ciprofloxacin levels were higher in the Follicular phase than in ovulatory and luteal phases and its levels in the ovulatory phase were lower than follicular and luteal phase. Mean concentrations of estrogen and progesterone in three phases of menstrual cycle are summerised in Table 1. The mean levels of estrogen were $28.5 \pm 16.5,98.5 \pm 110.7$ and $101.26 \pm 85.7 \mathrm{pg} / \mathrm{ml}$ in follicular, ovulatory and luteal phases respectively. The mean levels of progesterone were $0.6 \pm 0.4,4.5 \pm 2.8$ and $8.8 \pm 7.2 \mathrm{ng} / \mathrm{ml}$ in follicular, ovulatory and luteal phases respectively. Mean values of various pharmacokinetic parameters of Ciprofloxacin obtained in three phases (Table 2) were compared with the values obtained in other two phases and for the calculation of percentage increase or decrease, follicular phase was treated as reference (Table 3). The mean $\mathrm{Vd} / \mathrm{f}$ value was increased by $53.56 \%$ in the ovulatory phase and $9.31 \%$ in luteal phase compared to follicular phase. The difference between mean $\mathrm{Vd} / \mathrm{f}$ values for follicular versus ovulatory phase $(\mathrm{P}<0.01)$ and luteal versus ovulatory phase $(\mathrm{P}<0.05)$ was statistically significant.The mean $\mathrm{V}_{\text {ss/f }}$ value was increased by $50.71 \%$ in the ovulatory phase and $6.3 \%$ in the lutealphase compared to follicular phase. The difference between mean $\mathrm{V}_{\text {ss/f }}$ values for follicular versus ovulatory phase $(\mathrm{P}<0.01)$ and luteal versus ovulatory phase $(\mathrm{P}<0.01)$ was statistically significant.

Mean $\mathrm{C}_{\max }$ of Ciprofloxacin was decreased by $20 \%$ in the ovulatory phase compared to that of follicular phase and was lowest of all the three values. Similar menstrual cycle phase dependent change in Cmax was observed in case of alcohol with a lowest value at mid-cycle ${ }^{25}$. The highest blood alcohol concentration was found in premenstrual phase of the cycle in women and its rate of absorption varied during the menstrual cycle and was lowest at mid-cycle ${ }^{26}$. The mean Cmax of Paracetamol was significantly lowered in the ovulatory phase than in the follicular phase ${ }^{27}$ due to increased first pass metabolism during ovulatory phase.

Hormonal level variations and consequently physiological changes influence the pharmacokinetics of drugs by altering the properties such as gastrointestinal motility, thereby drug absorption, plasma protein levels as it alters protein binding, volume of distribution, drug metabolism and elimination. Higher levels of progesterone in luteal phase has smooth muscle relaxing effect, enhances the retention time of ingested material in small intestine, thereby it alters gastrointestinal transit and inturn drug absorption ${ }^{28}$. Hormone induced alterations in gastrointestinal motility are frequently reported by women during the luteal phase of the menstrual cycle $^{29}$. Delayed gastrointestinal transit resulting from high progesterone levels potentially inhibit Lithium absorption, while the exaggerated gastrointestinal motility in the final days of the cycle due to decreased levels 
of progesterone lead to a reversal of the effect ${ }^{30}$. In concurrence with this, in the present study also progesterone levels were significantly high during luteal phase and the $\mathrm{AUC}_{0-\infty}$ of Ciprofloxacin i.e, bioavailability was decreased in luteal phase by $20 \%$ than follicular phase.

Significant changes in endogenous sex hormone concentrations occur during the menstrual cycle and pregnancy, leading to alterations in protein binding, distribution and clearance ${ }^{31}$. Follicular phase has higher circulating levels of $\alpha-1$ acid glycoprotein (AAG), influence protein binding and changes free drug concentration, AAG concentrations are higher during the first week of the menstrual cycle than at other times ${ }^{32}$. It is expected that a decrease in available binding protein reduces the extent of drug protein binding, increases free drug fraction only for highly bound drugs. Alterations in protein binding affect steady-state unbound drug concentration, volume of distribution and drug half-life in a complex non-linear fashion that depends on hepatic extraction ratio and baseline parameters ${ }^{33}$.

Specifically, highly bound drugs with high extraction ratios (eg.Tricyclic Antidepressants, Verapamil) are expected to have increased free fraction, increased volume of distribution and increased boilogical half-life (for drugs with large volume of distribution). In the present study, volume of distribution was significantly lower in follicular and luteal phases compared to ovulatory phase could be due to increased protein binding of drug, as Ciprofloxacin is highly plasma protein bound drug i.e., about $75-85 \%$. The binding of Baclofen to neocortical membranes was varied as a function of the estrous cycle, with the lowest binding during the estrous stage in adult rat $^{34}$. Although such menstrual cycle related drug distribution changes in humans are yet to be investigated, in this study, the mean apparent volume of distribution and volume of distribution at steady state were increased by $53.76 \%$ and $50.71 \%$ respectively during the ovulatory phase compared to follicular and luteal phases and these differences were statistically significant.

Mean AUC and $\mathrm{C}_{\max }$ of Ciprofloxacin were decreased and clearance was increased in luteal phase compared to follicular phase. In the previous study with Ranitidine similar changes were observed ${ }^{35}$. Large fluctuations in hormone concentration throughout the menstrual cycle potentially impact hepatic enzyme activity and affect the metabolism of drugs. Progesterone inhibit and induce hepatic enzyme activity ${ }^{36-38}$. Estrogens inhibits the metabolism of many drugs by inhibiting liver microsomal enzymes and androgens stimulate microsomal enzymes ${ }^{38}$. Non specific CYP substrates exhibit higher clearance and lower AUC at ovulation with prolonged clearance in the luteal phase $\mathrm{e}^{39}$. Sex differences in drug metabolism and elimination are mainly related to steroid hormonal levels. CYP3A4, which is responsible for themetabolism of over $50 \%$ of drugs exhibit higher activity in women compared to men ${ }^{40,41}$.

Inter individual variability in Methyl prednisolone disposition among young women also attributed to menstrual cycle variability in CYP3A4 activity ${ }^{42}$. In contrast, the similarity in Alfentanil diposition on day 2, 13 and 21 suggest that hepatic cytochrome P4503A4 activity does not vary significantly with hormonal changes during the menstrual cycle ${ }^{43}$. Menstrual cycle changes in uterine P4503A4 content, apparently do not influence Alfentanil clearance as it metabolises Alfentanil to a lesser extent when compared with liver enzymes ${ }^{44}$. Similarly, Midazoram clearance was not significantly different during three major phases of the mensrual cycle, strongly suggests that hepatic CYP3A4 activity does not vary significantly with hormonal changes ${ }^{45}$ during the menstrual cycle atleast on day 2, 13 and 21. Though non-significant, Theophylline clearance was increased and half-life was decreased in luteal phase compared to follicular phase ${ }^{46}$. In our study, Ciprofloxacin half-life was decreased and clearance was increased in luteal phase compared to follicular phase.

Ovulatory phase has higher clearance and smaller AUC and t1/2 of Antipyrine due to estrogenprogesterone surges in mid-cycle ${ }^{12}$. Similar observations in the plasma metabolism of Methaqualone were reported $^{46}$. Higher clearance and smaller $\mathrm{AUC}_{0-\infty}$ of Ciprofloxacin in ovulatory phase compared to follicular phase was observed might be due to estrogen-progesterone surge.Plasma Vasopressin, Aldosterone concentrations and renin activity are significantly higher in the luteal phase than in the follicular phase of the menstrual cycle when plasma estrogen levels are highest ${ }^{47}$. Urinary kallikrein excretion is also greater in the luteal phase ${ }^{48}$. Another study found urinary sodium excretion to decline in the periovulatory phase. These changes have the potential to alter the distribution and excretion of medications. Both volume of distribution and clearance of Ciprofloxacin were increased in luteal phase compared to follicular phase in our study. Inter and intra-patient variation in the AUC might be due to variation in estrogen levels. A significant negative relationship was found between AUC and estradiol levels suggesting that Zidovudine glucuronidation change in relation to the menstrual cycle phase ${ }^{49}$. Similar results i.e. negative relationship between $\mathrm{AUC}_{0-\infty}$ of Ciprofloxacin and estradiol levels observed in ovulatory and luteal phases in our study.

Except $\mathrm{Vd}_{\mathrm{f} / \mathrm{f}}$ and $\mathrm{V}_{\mathrm{ss} / \mathrm{f}}$, menstrual cycle phases did not significantly affect the pharmacokinetic profile of Ciprofloxacin in terms of $\mathrm{C}_{\max }, \mathrm{T}_{\max }, \mathrm{AUC}_{0-\infty}, \mathrm{AUMC}_{0-\infty}, \mathrm{t}_{1 / 2}, \mathrm{MRT}$, clearance and absorption rate constant. This is in consistent with studies using Nitrazepam ${ }^{50}$, Alprazolam ${ }^{51}$ and Triazolam ${ }^{52}$.During the follicular phase of the menstrual cycle, the levels of estrogen and progesteroneare relatively low, whereas during the mid-luteal phase, ovarian steroid hormone levelsare high ${ }^{53}$. Mean $\mathrm{C}_{\max }, \mathrm{t}_{1 / 2}$ and AUC of Cocaine were decreased in luteal phase 
compared to follicular phase after intravenous administration. After intranasal Cocaine, women had higher peak plasma levels during the follicular phase than during the lutealphase ${ }^{54}$. The $\mathrm{C}_{\max }, \mathrm{t}_{1 / 2}$ and $\mathrm{AUC}_{0-\infty}$ of Ciprofloxacin were decreased in lutealphase compared to follicular phase in the present study.

\section{Conclusion}

From the above observations it can be concluded that, phase specific menstrual hormonal changes influenced Ciprofloxacin pharmacokinetics to a lesser extent and $\mathrm{V}_{\mathrm{d} / \mathrm{f}}$ and $\mathrm{V}_{\mathrm{ss} / \mathrm{f}}$ were significantly altered. Mean plasma concentrations of Ciprofloxacin were higher in follicular phase than in ovulatory and luteal phases.

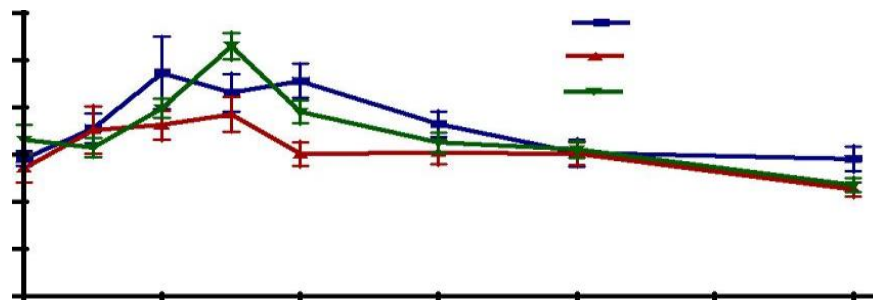

Fig. 1: Mean plasma concentration versus time profile of Ciprofloxacin during three phases of menstrual cycle in epileptic patients

Table 1: Mean levels of hormones in epileptic patients using Ciprofloxacin inthree phases of menstrual cycle $(n=12)$

\begin{tabular}{|l|l|l|l|l|}
\hline Hormone & \multicolumn{2}{|c|}{ Follicular phase } & \multicolumn{1}{c|}{ Ovulatory phase } & \multicolumn{1}{c|}{ Luteal phase } \\
\hline Estrogen $(\mathrm{pg} / \mathrm{ml})$ & 38.5 & \pm 16.9 & $98.5 \pm 110.7$ & $101.26 \pm 85.7$ \\
\hline Progesterone $(\mathrm{ng} / \mathrm{ml})$ & 0.6 & \pm 0.4 & $4.0 \pm 2.8$ & $9.1 \pm 7.2$ \\
\hline
\end{tabular}

Table 2: Pharmacokinetic parameters of Ciprofloxacin during three phases( $\mathrm{n}=12)$

\begin{tabular}{|c|c|c|c|c|c|}
\hline Pharmacokinetic & Follicular phase & Ovulatory phase & Luteal phase & Statistical & \multirow[t]{2}{*}{ p-value } \\
\hline parameter & Mean \pm SD & Mean \pm SD & Mean \pm SD & significance & \\
\hline Cmax (ug/ml) & $0.61 \pm 0.28$ & $0.49 \pm 0.18$ & $0.56 \pm 0.09$ & NS & 0.1817 \\
\hline Tmax (hrs) & $3.25 \pm 1.12$ & $3.3 \pm 1.89$ & $3.1 \pm 0.45$ & NS & 0.8792 \\
\hline AUC0-t & \multirow[t]{2}{*}{$4.30 \pm 1.53$} & \multirow[t]{2}{*}{$3.65 \pm 1.09$} & \multirow[t]{2}{*}{$4.03 \pm 0.83$} & \multirow[t]{2}{*}{ NS } & \multirow[t]{2}{*}{0.2312} \\
\hline (ug/ml/hr) & & & & & \\
\hline $\mathrm{AUC}_{0-\infty}$ & \multirow[t]{2}{*}{$11.09 \pm 5.65$} & \multirow[t]{2}{*}{$8.12 \pm 2.48$} & \multirow[t]{2}{*}{$8.90 \pm 3.44$} & \multirow[t]{2}{*}{ NS } & \multirow[t]{2}{*}{0.0652} \\
\hline (ug/ml/hr) & & & & & \\
\hline $\mathrm{AUMC}_{0-\infty}$ & \multirow[t]{2}{*}{$301.27 \pm 237.31$} & \multirow[t]{2}{*}{$193.09 \pm 81.03$} & 208.15 & \multirow[t]{2}{*}{ NS } & \multirow[t]{2}{*}{0.0983} \\
\hline (ug/ml/hxh) & & & \pm 149.47 & & \\
\hline $\mathrm{t}_{1 / 2}(\mathrm{hrs})$ & $15.21 \pm 7.07$ & $14.9 \pm 4.98$ & $13.6 \pm 5.64$ & NS & 0.6564 \\
\hline \multirow[t]{2}{*}{$\mathrm{Vd} / \mathrm{f}(\mathrm{ml} / \mathrm{kg})$} & $17583.87 \pm$ & 27002.78 & 19222.6 & Fvs $\mathrm{O}<0.01^{*} *$ & \multirow[t]{2}{*}{0.0058} \\
\hline & 8562.70 & \pm 12436.76 & \pm 6404.20 & $\mathrm{~L}$ vs $\mathrm{O}<0.05^{*}$ & \\
\hline \multirow[t]{2}{*}{ Vss/f (ml/kg) } & $19380.16 \pm$ & 29208.55 & 20606.94 & $\mathrm{~F}$ vs $\mathrm{O}<0.01 * *$ & \multirow[t]{2}{*}{0.0051} \\
\hline & 8749.11 & \pm 13470.34 & \pm 6179.62 & $\mathrm{~L}$ vs $\mathrm{O}<0.01^{* * *}$ & \\
\hline \multirow[t]{2}{*}{ CLs/f(ml/hr/kg) } & \multirow[t]{2}{*}{$965.33 \pm 670.09$} & \multirow[t]{2}{*}{$1151.87 \pm 429.09$} & 1091.78 & \multirow[t]{2}{*}{ NS } & \multirow[t]{2}{*}{0.5195} \\
\hline & & & \pm 432.89 & & \\
\hline MRT(hr) & $23.99 \pm 10.00$ & $23.43 \pm 7.47$ & $20.9 \pm 7.64$ & NS & 0.4869 \\
\hline $\begin{array}{l}\mathrm{Ka} \\
\text { ळl) }\end{array}$ & $0.132 \pm 0.081$ & $0.119 \pm 0.045$ & $0.165 \pm 0.121$ & NS & 0.2611 \\
\hline
\end{tabular}

Values are expressed as Mean $\pm \mathrm{SD}, * \mathrm{P}<0.05$ is considered as statistically significant

$\mathrm{F}=$ Follicular phase; $\mathrm{O}=$ Ovulatory phase; $\mathrm{L}=$ Luteal phase.

Values are expressed as Mean $\pm \mathrm{SD} ; * \mathrm{P}<0.05$ is considered as statistically significant

\section{References}

[1]. Morrell MJ. Hormones and epilepsy through the lifetime. Epilepsia. 1992;33(Suppl):S49-S61.

[2]. Murialdo G, Galimberti CA, Magri F, Sampaolo P, Copello F, Gianelli MV, Gazzerro E, Rollero A, Deagatone C, Manni R, Ferrari E,Polleri A and Tartara A. Menstrual cycle and ovary alterations in women with epilepsy on antiepileptic therapy. J Endocrinol Invest. 1997;20:519-526.

[3]. Klein P and Herzog AG. Hormonal effects on epilepsy in women. Epilepsia. 1988;39(Suppl 8):S9-S16.

[4]. Perucca E and Crema A. Plasma protein binding of drugs in pregnancy. Clin Pharmacokinet. 1982; 7:336-352.

[5]. Yerby MS. Problems and management of the pregnant woman with epilepsy. Epilepsia. 1987; 28(Suppl):S29-S36.

[6]. Bernus I, Hooper WD, Dickinson RG and Eadie MJ. Metabolism of Ciprofloxacin and co-administered anticonvulsants during pregnancy. Epilepsy Res. 1995;21(1):65-75.

[7]. Malone FD and D'Alton ME. Treatment of epilepsy in pregnancy. Drugs. 1999; 57(4):535- 544.

[8]. Shenfield GM. Oral contraceptives. Are drug interactions of clinical significance? Drug Safety. 1993; 9:21- 37

[9]. Mattson RH, Cramer JA, Darney PD and Naftolin F. Use of oral contraceptives by women with epilepsy. JAMA. 1986; 256:238240. 
[10]. Al-dahan MI, Jalilian- Tehrani MH, Thalmann RH. Regulation of gamma amino butyric acid B (GABA-B) receptors in cerebral cortex during the estrous cycle. Brain Res. 1994;640(1-2):33-39.

[11]. Krauss GL, Brandt J, Campbell M, Plate C and Summerfield M.46:1534-1539.

[12]. Reddy DS. Pharmacology of catamenial epilepsy. Clin Pharmacol. 2004;26(7):

[13]. Nayak VK, Kshirsagar NA, Desai NK and Satoskar RS. Influence of menstrual cycle on antipyrine pharmacokinetics in healthy Indian female volunteers. Br J Clin Pharmacol. 1988;26:604-606.

[14]. Bruguerolle B, Toumi M, Faraj F, Vervloet D and Razzouk H. Influence of the menstrual cycle on theophylline pharmacokinetics in asthmatics. Eur J Clin Pharmacol. 1990;39:59-61.

[15]. Kamimori GH, Joubert A, Otterstetter R, Santaromana M and Eddington ND. The effect of menstrual cycle on the pharmacokinetics of caffeine in normal, eumenorrheic females. Eur J Clin Pharmacol. 1999;55:445-449.

[16]. Ebid A, Shelton M, Adams J, Cordaro J, Gugino L, Maliszewski M, Colomaio R, Hewitt R and Morse G. Menstrual cycle and zidovudine pharmacokinetics in HIV- infected women. Clin Drug Invest. 2001;21(10):715-726.

[17]. Kharasch ED, Mautz D, Senn T, Lentz G and Cox K. Menstrual Cycle variability in midazolam pharmacokinetics. J Clin Pharmacol. 1999;39:275-280.

[18]. Danhof M and Breimer DD. Therapeutic drug monitoring in plasma. Clin Pharmacokinet. 1978; 3:39-57.

[19]. Drobitch RK and Svensson CK. Therapeutic drug monitoring in plasma. An update Clin Pharmacokinet. 1992;23:365-379.

[20]. Killmann S and Thaysen JH. The permeability of the human parotid gland to a series of sulfonamide compounds, paraaminohippurate and inulin. Scand J Clin. Lab Invest. 1955;7:86-91.

[21]. Borzelleca JF and Cherrick HM. The excretion of drugs in plasma. Antibiotics. J Oral Ther Pharmacol. 1965;2:180.

[22]. Borzelleca JF and Doyle CH. Excretion of drugs in plasma. Salicylate, barbiturate, sulfonamide. J Oral Ther Pharmacol. 1966;3:104.

[23]. Borzelleca JF and Putney JW. A podel for the movement of salicylate across the parotid epithelium. J Pharmacol Exp Ther. 1970;174:527.

[24]. Schramm W and Smith RH. An infiltrate of plasma collected in situ as a biological sample for diagnostic evaluation. Clin Chem. 1991;37:114-115.

[25]. Kishore P, Rajnarayan K. Mada S. Reddy, Vidya Sagar J and Krishna DRK. Validated high performance liquid chromatographic method for simultanerous determination of phenytoin, phrnobarbitol and Ciprofloxacin in human serum. Arznium Forsch Drug Res. 2003;53(11):763-768

[26]. Lammers SM, Mainzer DE and Breteler MH. Do alcohol in women vary due to menstrual cycle. Addiction. 1995; 90(1):23-30.

[27]. Jones BM and Jones MK. Alcohol effects in women during the menstrual cycle. Annals of the New York Academy of Sciences. 1976;273:576-587.

[28]. Sandhya RG, Ramesh RB, Samba MB and Rambhau D. Influence of menstrual cycle on the paracetamol through plasma compartment in healthy subjects. Ther Drug Monitor. 2002;24: 497-501.

[29]. Singer JS and Brandt LJ. Pathophysiology of the gastrointestinal tract during pregnancy. Am J Gastroenterol. 1991;86:1695-1715.

[30]. Wald A, Van Thiel DH, Hoechstetter L, Gavaler JS, Egler KM, Verm R, Scott L and Lester R. Gastrointestinal transit: The effect of the menstrual cycle. Gastroenterol. 1981; 80:1497-1500.

[31]. Chamberlein S, Hahn PM, Casson P and Reid RL. Effect of menstrual cycle phase and oral contraceptive use on serum lithium levels after a loading dose of lithium in normal women. Am J Psych, 1990;147(7):907-909.

[32]. Lam JR and Connor JD.The influence of endogenous and exogenous sex hormones in adolescents with attention to oral contraceptives and anabolic steroids. J Adolesc Health. 1994; 15(8):630-634.

[33]. Parish RC and Spivey C. Influence of menstrual cycle phase on serum concentrations of a-1 acid glycoprotein. Br J Clin Pharmacol. 1991;31:197-199.

[34]. Wilkinson GR and Shand DG. A physiological approach to hepatic drug clearance. Clin Pharmac Ther. 1975;18:377-390.

[35]. Al-dahan MI, Jalilian- Tehrani MH and Thalmann RH. Regulation of gamma amino butyric acid B (GABA-B) receptors in cerebral cortex during the estrous cycle. Brain Res. 1994;640(1-2):33-39.

[36]. Perez JF, Olguin HJ, Perez CF, Guille GP, Perez AG, Vieyra AG, Lopez AT, Portugal MC, Asseff IL. Effects of gender and phase of the menstrual cycle on the kinetics of ranitidine on healthy volunteers. Chronobiology International. 2003;20:485- 494.

[37]. Wilson JT. Developmental pharmacology: a review of its application to clinical and basicscience. Annu Rev Pharmacol. 1972; 423457.

[38]. Blackham H and Spencer PS. The effects of estrogens and progestins on the response of mice to barbiturates. Br J Pharmacol. 1969; 37:129-139

[39]. Gibaldi M. Biopharmaceutics and clinical pharmacokinetics. $4^{\text {th }}$ ed. Philadelphia/London: Lee and Feibger. 1991;14-23.

[40]. Backstrom T and Jorpes P. Serum phenytoin, phenobarbital, Ciprofloxacin, albumin; and plasma estradiol, progesterone concentrations during the menstrual cycle in women with epilepsy. Acta Neurologica Scandinavica. 1979;59:63-71.

[41]. Harris RZ, Benet LZ and Schwartz JB. Gender effects in pharmacokinetics and pharmacodynamics of Drugs. Br J Clin Pharmacol. 1999;50(2):222-239.

[42]. Gleiter CH, Gundert-Remy U. Gender differences in pharmacokinetics. Eur J Drug Metab Pharmacokinet. 1996; 21:123-128.

[43]. Lew KH, Ludwig EA, Milad MA and Donovan K, Middleton E Jr, Ferry JJ, Jusko WJ. Gender based effects on methylprednisolone pharmacokinetics and pharmacodynamics. Clin Pharmacol Ther. 1993;54:402-414.

[44]. Kharasch ED, Russell M, Garton K, Lentz G, Bowdle TA and Cox K. Assessment of cytochrome P450 3A4 Activity during the menstruasl cycle using Alfantanil as a noninvasive probe. Clinical investigation, Anesthesiology. 1997;87(1):26-35.

[45]. Schuetz JD, Kauma S and Guzelian PS. Identification of the fetal liver cytochrome CYP3A7 in human endometrium and placenta. J Clin Invest, 1993;92:1018-1024.

[46]. Nagata K, Ishitabi K, Yamamota Y, Ikeda T, Mori S, Matsumato Y and Sasaki T. Increased theophylline metabolism in the menstrual phase of healthy women. J Allergy Clin Immunol. 1997;100(1):39-43.

[47]. Wilson K, Oram M, Horth CE and Burnett D. The influence of menstrual cycle on the metabolism and clearance of methaqualone. Br J Clin Pharmac . 1982;14: 333-339.

[48]. Chidambaram M, Duncan JA, Lai VS, Cattran DC, Floras JS. Variation in the Renin Angiotensin System throughout the normal menstrual cycle. J Am Soc Nephrol. 2002;13:446-452.

[49]. Reed RG, Pearson TA, Stewart PW. Heiling VJ and Jensen HD. Variance in serum lipids and lipoproteins with menstrual cycle in premenstrual women is no greater than variance in postmenstrual women or men. Circulation. 1995; 91:923.

[50]. Olson BR, Forman MR, Lanza E, McAdam PA, Beecher G, Kimzey LM and Campbell WS. Relation between sodium balance and menstrual cycle symptoms in normal women. Ann Inern. Med. 1996;125:564-567.

[51]. Jochemsen R, Vander graaff M, Boeijinga JK and Breimer DD. Influence of sex, menstrual cycle and oral contraception on the 
disposition of nitrazepam. Br J Clin Pharmacol. 1982;13:319-324.

[52]. Kirkwood C, Moore A, Hayes P, DeVane CL and Pelonero A. Influence of menstrual cycle and gender on alprazolam pharmacokinetics. Clin Pharmacol Ther. 1991;50:404- 409.

[53]. Ruktalis M and De-Wit H. Effects of Triazolam at Three Phases of the Menstrual Cycle. J Clin Psychopharmacol. 1999;19(5):450458.

[54]. Yen S and Jaffe R. Reproductive endocrinology, physiology, pathophysiology and clinical management. Philadelphia: W.B.Saunders. 1991; 409-459.

[55]. Mendelson JH, Mello NK, Sholar MB, Siegal AJ, Kaufman MJ, Levin JM, Renshaw PF and Cohen BM. Cocaine pharmacokinetics in men and in women during the follicular and luteal phases. 